\title{
Cost-Effectiveness Analysis of Implantable Cardioverter Defibrillator Therapy for Primary Prevention Patients with Additional Risk Factors in Brazil
}

\author{
Kael Wherry, ${ }^{\circledR}$ Reece Holbrook, ${ }^{1}$ Lucas Higuera, ${ }^{1}$ Francis Fujii, ${ }^{\circledR}$ Diego A. Rodriguez ${ }^{\circledR}{ }^{\circledR}$ \\ Medtronic, plc, Mineápolis, Minnesota - EUA \\ Cardiology - Electrophysiology, Fundación Cardioinfantil, ${ }^{2}$ Bogotá - Colombia
}

\section{Abstract}

Background: Implantable cardiac defibrillators (ICDs) therapy for primary prevention (PP) of sudden cardiac arrest (SCA) is well-established but underutilized globally. The Improve SCA study has identified a cohort of patients called 1.5 primary prevention (1.5PP), based on PP patients with the presence of documented risk factors: non-sustained ventricular tachycardia, frequent premature ventricular contractions, left ventricular ejection fraction $<25 \%$, and pre-syncope or syncope.

Objective: This study evaluated the cost-effectiveness of ICD therapy compared to no ICD among 1.5PP patients in the Brazilian public healthcare system.

Methods: Modified inputs to a published Markov model were applied to compare costs and outcomes of ICD therapy to no ICD therapy from the Brazilian payer's perspective. Mortality and utility estimates were obtained from the IMPROVE SCA trial. Additional effectiveness inputs were sourced from the literature. Cost inputs were obtained from the Brazilian Unified Health System and the Ministry of Health. Costs were discounted at $4.7 \%$; quality-adjusted life years (QALYs) were discounted at $1.45 \%$. This study applied a willingness-to-pay (WTP) value of three times Brazil's gross domestic product (GDP) in 2017, R\$105,723 (Brazilian Real).

Results: The total discounted lifetime costs for ICD therapy were $R \$ 100,920$ compared to $R \$ 43,866$ for no ICD therapy. Total discounted QALYs for ICD therapy and no ICD therapy were 9.85 and 7.15 , respectively. The incremental cost effectiveness ratio was $\mathrm{R} \$ 21,156$ per QALY and less than the $\mathrm{R} \$ 105,723$ WTP threshold. Results from sensitivity analyses were consistent with base case results.

Conclusions: ICD therapy compared to no ICD therapy is cost-effective in the 1.5PP population in Brazil.

Keywords: Cardiovascular Diseases/prevention andcontrol; Defibrillators,Implantable/economy; Cost-Effectiveness Evaluation; Technology Assessment, Biomedical; Death, Sudden Cardiac; Health Evaluation.

\section{Introduction}

Evidence for the use of implantable cardioverter defibrillators (ICDs) for primary prevention of sudden cardiac arrest (SCA) in patients with moderately symptomatic heart failure and reduced systolic function has been well-established through multiple randomized clinical trials ${ }^{1,2}$ and confirmed in realworld observational evidence. ${ }^{3}$ This evidence has led to strong recommendations for ICD use in society guidelines ${ }^{4,5} \odot$ and has been leveraged to establish the cost-effectiveness of ICD therapy in multiple healthcare systems. ${ }^{6,7}$ Despite this strong evidence base, ICD therapy remains underutilized globally, due at least in part to cost considerations and the lack of reimbursement. ${ }^{8}$

The Improve SCA study has identified a high-risk subset of primary prevention patients called 1.5 primary prevention (PP) based on the presence of at least one of the following documented risk factors: non-sustained ventricular tachycardia (NSVT), frequent premature 
ventricular contractions (PVCs) $>10 / \mathrm{h}$, left ventricular ejection fraction $(\mathrm{LVEF})<25 \%$, pre-syncope, or syncope. ${ }^{9}$ Improve SCA patients with $1.5 \mathrm{PP}$ characteristics were found to have a higher rate of treatment with appropriate therapy than PP patients, and when treated with an ICD, 1.5 PP patients experienced a $49 \%$ relative risk reduction in all-cause mortality compared to normal PP patients. ${ }^{10}$

While the cost-effectiveness of ICD therapy for primary prevention patients has been established, the cost-effectiveness of ICD therapy for 1.5 PP patients is not well-known. The 1.5 PP cohort could be used to prioritize health care resources in geographies where such resources are insufficient to cover the full PP population. To that end, this study sought to estimate the lifetime cost and benefits of ICD therapy in the 1.5 PP patient population in Brazil, where ICD therapy is underutilized but may be cost-effective. ${ }^{11}$ To the best of our knowledge, this is the first evaluation of the cost-effectiveness of ICD therapy compared to no ICD therapy among 1.5 PP patients from the perspective of the Brazilian public healthcare system.

\section{Methods}

An existing Markov decision model was applied to estimate the lifetime cost, quality of life, survival, and incremental cost-effectiveness of ICD therapy versus no ICD therapy for a Brazilian population at risk for SCA (1.5 PP). ${ }^{6}$ No ICD therapy was selected as the control, rather than pharmacologic therapy, based on SCD-HeFT study findings that indicated no significant difference in the risk of death between treatment with amiodarone and treatment with a placebo. ${ }^{1}$ This evaluation was conducted in the setting of the Brazilian public healthcare system, where health technology assessments are overseen by the National Commission for the Incorporation of Technology (CONITEC). ${ }^{12}$ Model inputs are shown in Table 1, and the model analysis was performed in Microsoft Excel, the details of which are described below.

\section{Model Structure}

The model follows a simulated cohort of 1,000 patients with a standard indication for PP ICD therapy and at least one 1.5 PP risk factor. The model is structured as a decision tree with two treatment arms, ICD therapy or no ICD therapy, followed by consecutive Markov models (Figure 1). Patients who enter the model in the ICD arm are at an initial risk of operative death or survival. Patients who survive the ICD surgery enter the Markov model in the well state. From the well state, ICD patients stay well or progress to ICD complications, sudden cardiac death, non-sudden cardiac death, non-cardiac death, or unknown death. Patients remain in the same state or progress to a different state at the beginning of each cycle, except for the complication state. Patients who experience an ICD complication remain in the complication state for only one cycle, then progress to continued ICD therapy or discontinued ICD therapy. In the event of therapy discontinuation, ICD patients stay well without ICD treatment or progress to sudden cardiac death, non-sudden cardiac death, non-cardiac death, or unknown death. Patients in the no ICD arm enter the model in a healthy state and remain well or progress to sudden cardiac death, non-sudden cardiac death, noncardiac death, or unknown death.

Patients incur costs and effects by progressing through the model in monthly increments over a lifetime (420 months); a lifetime perspective allows the model to account for all costs incurred by patients that survive without a sudden cardiac arrest event. Patients in both treatment arms incur monthly inpatient and outpatient costs. In the ICD therapy arm, patients also incur the cost of the device and ICD implant procedure. ICD patients who remain alive long enough to require a device replacement incur additional device and procedure costs at the time of replacement. ICD patients may receive an inappropriate shock or other ICD-related complication that incurs a cost and affects treatment adherence. After experiencing an inappropriate shock or other ICD-related complication, patients remain in the ICD therapy arm, receiving ICD treatment, or progress to discontinued use of ICD therapy. In this study it was assumed that ICD patients who discontinue their use of ICD therapy have the same mortality risk as patients in the no ICD arm.

\section{Clinical Data}

Clinical inputs to the model were based on Improve SCA clinical study results, the United States (US) National ICD registry, literature, and administrative claimsbased analyses. Improve $\mathrm{SCA}^{10}$ is the largest ICD study conducted in emerging markets and has enrolled patients from 17 different countries. The non-randomized study tracked outcomes in patients with primary, secondary, and 1.5 PP indications for ICD therapy. The probability of implant-related operative death (0.0002) was based 
Table 1 - Model Input Parameters

\begin{tabular}{|c|c|c|c|c|}
\hline Model Parameters & Base Case Value & Standard Error & Distribution & Reference \\
\hline \multicolumn{5}{|l|}{ Monthly Risk of Mortality (ICD Therapy) } \\
\hline Sudden cardiac death & 0.0007 & 0.0003 & Beta & \multirow{4}{*}{$(10)$} \\
\hline Non-sudden cardiac death & 0.0014 & 0.0004 & Beta & \\
\hline Non-cardiac death & 0.0005 & 0.0003 & Beta & \\
\hline Unknown death & 0.0013 & 0.0003 & Beta & \\
\hline \multicolumn{5}{|l|}{ Monthly Risk of Mortality (No ICD Therapy) } \\
\hline Sudden cardiac death & 0.0028 & 0.0005 & Beta & \multirow{4}{*}{$(10)$} \\
\hline Non-sudden cardiac death & 0.0021 & 0.0004 & Beta & \\
\hline Non-cardiac death & 0.0010 & 0.0004 & Beta & \\
\hline Unknown death & 0.0014 & 0.0004 & Beta & \\
\hline \multicolumn{5}{|l|}{ ICD-Related Probabilities } \\
\hline Initial operative death & 0.0002 & 0.00002 & Beta & (13) \\
\hline Continue ICD therapy after shock & 0.0034 & 0.0002 & Beta & \multirow{2}{*}{$(2,14,15,19,35,36)$} \\
\hline Discontinue ICD therapy after shock & 0.0001 & 0.00007 & Beta & \\
\hline Lead replacement (initial implant) & 0.0004 & 0.0005 & Beta & $(18,22)$ \\
\hline Lead replacement (replacement implant) & 0.0008 & 0.0009 & Beta & (23) \\
\hline Lead dislodgement (initial implant) & 0.018 & 0.0012 & Beta & $(18,22)$ \\
\hline Lead dislodgement (replacement implant) & 0.005 & 0.0009 & Beta & (23) \\
\hline ICD infection (initial implant) & 0.0244 & 0.0049 & Beta & (17) \\
\hline ICD infection (replacement implant) & 0.0432 & 0.0064 & Beta & (20) \\
\hline
\end{tabular}

\begin{tabular}{lc}
\hline ICD implant procedure (initial) & $\mathrm{R} \$ 1,738$ \\
\hline ICD implant procedure (replacement) & $\mathrm{R} \$ 1,738$ \\
\hline Lead replacement & $\mathrm{R} \$ 827$ \\
\hline ICD generator removal & $\mathrm{R} \$ 742$ \\
\hline ICD lead dislodgement & $\mathrm{R} \$ 742$ \\
\hline ICD inappropriate shock & $\mathrm{R} \$ 500$ \\
\hline ICD infection & $\mathrm{R} \$ 30,000$ \\
\hline Monthly inpatient cost & $\mathrm{R} \$ 166$ \\
\hline Monthly outpatient cost & $\mathrm{R} \$ 354$
\end{tabular}

\section{Utility}

\begin{tabular}{lccc}
\hline Annual utility of heart failure patient & 0.837 & 0.007 & Beta \\
\hline ICD complication state & 0.7408 & 0.0112 & Beta \\
\hline
\end{tabular}

Abbreviations: ICD, Implantable Cardioverter-Defibrillator 


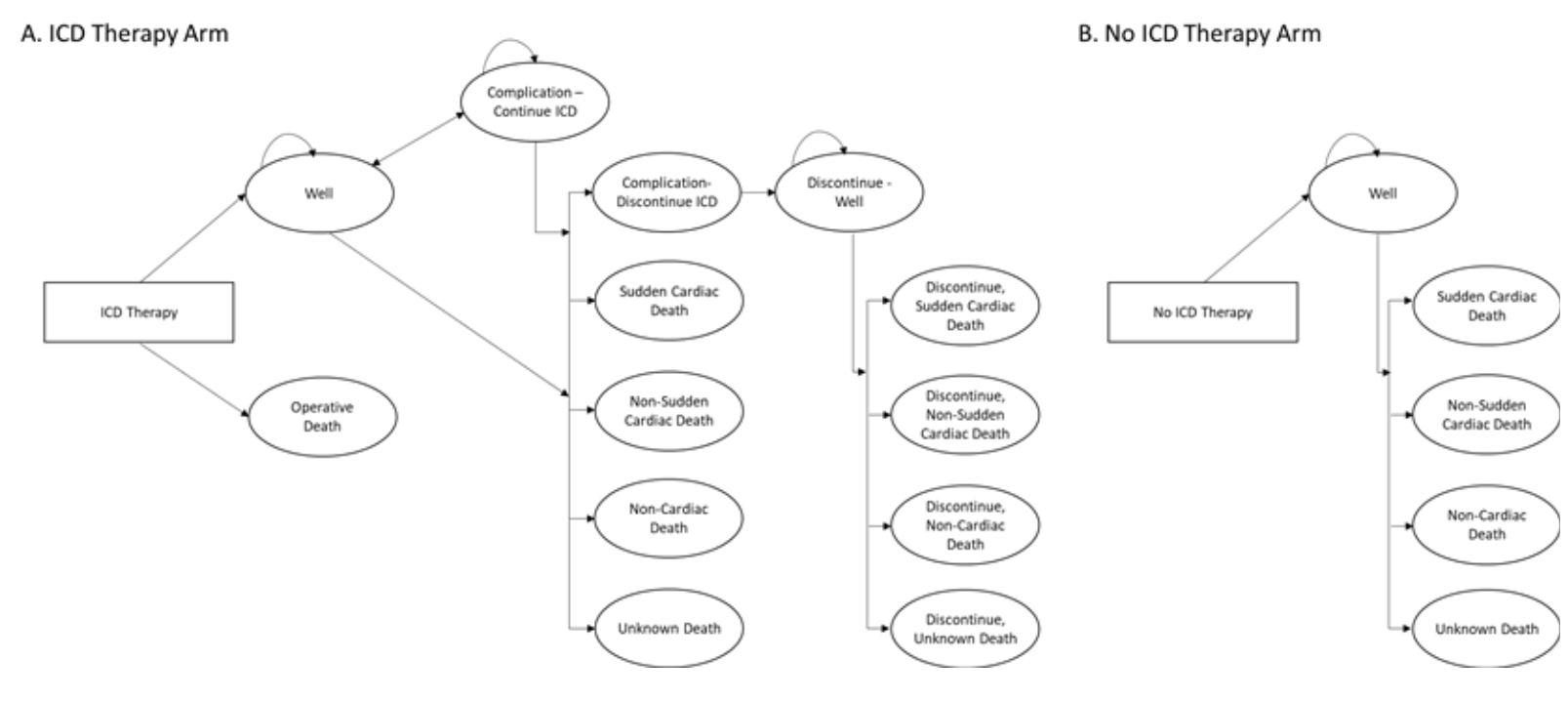

Figure 1 - Model schematic. Model states are represented by ovals; arrows indicate transitions between states. ICD, implantable cardioverter defibrillator. Panel A shows model states in ICD therapy arm. Panel B shows model states in the control arm.

on the US National ICD Registry and applied only to the ICD treatment arm..$^{13}$ The probabilities of sudden cardiac death, non-sudden cardiac death, non-cardiac death, or unknown death were based on results from the Improve SCA study. Inappropriate shock probability was derived from a weighted average based on the MADIT RIT, ADVANCE III, PROVIDE, and PainFree SST clinical trials that demonstrated a reduction in inappropriate shock rates due to device programming. 2,14-16 Probabilities of lead failure or dislodgement after initial implant were based on studies of annual incidence of lead failure and ICD lead dislodgement at one year after implant, $0.45 \%$ and $1.8 \%$ respectively. ${ }^{17,18}$ Probability of lead dislodgement or replacement after ICD replacement was based on data from the REPLACE registry, which reported a $1 \%$ combined dislodgement and replacement rate. ${ }^{19}$. It was assumed that half of the combined rate reported in the REPLACE registry could be attributed to lead failure $(0.5 \%)$ and half could be attributed to lead dislodgement $(0.5 \%)$. The one-year probability of lead infection after initial implant $(1.22 \%)$ and device replacement $(2.16 \%)$ was also estimated by means of a retrospective data analysis based on administrative claims from a large US insurance company. ${ }^{20}$ The lifetime risk of lead infection after the first year of an initial or replacement implant was double the value of the one-year claims-based probability. ${ }^{17,18}$

\section{Economic Data}

Device related costs and long-term health care use costs associated with heart disease were modeled over a lifetime. To represent the perspective of the Brazilian public healthcare system, several cost inputs to the model were based on the medical procedure price list published by the Brazilian Unified Health System in 2017. ${ }^{21,22}$ The 2017 costs were updated to 2018 Brazilian Reals (R\$) using the Brazil-specific average inflation rate based on the consumer price index, 3.66\%. The cost of inappropriate shock was derived from an analysis of procedures commonly performed at encounters for shocks. ${ }^{23}$ Long-term inpatient and outpatient costs were estimated from a publication on the costs of heart failure in Colombia . ${ }^{24}$ To obtain ICD-specific costs, the long-term inpatient costs were multiplied by the average number of hospitalizations per year for patients recommended for ICD therapy based on the SCD-HeFT trial. Costs were discounted at $4.7 \%$; quality-adjusted life years (QALYs) were discounted at $1.45 \%$, according to CONITEC guidelines. ${ }^{25}$.

\section{Health-Related Quality of Life}

Quality of life was based on an analysis of EQ5D data collected in the PainFree SST clinical trial. Brazil-specific utilities were derived by mapping each 
patient's EQ-5D state, using country specific societal preferences. ${ }^{26}$ The baseline utility for both treatment arms was assumed to be the same. Patients who experienced an ICD-related complication received a short-term utility decrement of 0.096 , which is equivalent to 3.5 days. ${ }^{27}$

\section{Construction of the ICER (w/WTP) and Sensitivity Analysis}

Total lifetime costs and quality-adjusted life years (QALYs) between ICD therapy and no ICD therapy were simulated to calculate the incremental cost effectiveness ratio (ICER). Both undiscounted and discounted results were calculated to best represent the time value of costs and outcomes. One-way sensitivity analysis and probabilistic sensitivity analysis were conducted to assess the impact of model inputs and parameter uncertainty. A willingness-topay (WTP) threshold value of $R \$ 105,723$ was used for this model. Our WTP value reflects an amount equal to three times the per capita gross domestic product (GDP) in Brazil in 2018, as recommended by the World Health Organization (WHO). ${ }^{28}$

\section{Results}

\section{Base case scenario}

Table 2 shows the results of the base-case scenario. ICD therapy for 1.5 prevention resulted in a benefit of 11.79 (discounted) and 13.41 (undiscounted) life-years saved, while no ICD therapy resulted in a benefit of 8.54 and 9.46 life-years saved, respectively. Measured in QALYs, the discounted benefit from ICD therapy is 9.85 and 7.15 from no ICD therapy, resulting in an incremental effectiveness of 2.70 QALYs. Discounted costs from ICD therapy and no ICD therapy account for $\mathrm{R} \$ 100,920$ and $\mathrm{R} \$ 43,866$, respectively. The ICER for ICD therapy is $\mathrm{R} \$ 21,156$ per QALY; ICD therapy for 1.5 prevention is cost-effective at $R \$ 105,723$, three times the Brazilian GDP per capita WTP threshold in the base case scenario. Moreover, ICD therapy is highly costeffective at the $\mathrm{R} \$ 35,241$ threshold of one GDP per capita.

\section{Sensitivity analyses}

Results of the one-way sensitivity analyses show that costs per QALY are more responsive to the

Table 2 - Base case scenario results

\begin{tabular}{|c|c|c|c|}
\hline Base Case Scenario Results & & ICD therapy & No ICD Therapy \\
\hline \multirow{6}{*}{ Undiscounted } & Aggregated costs & $\mathrm{R} \$ 139,120$ & $\mathrm{R} \$ 59,008$ \\
\hline & Differential cost & \multicolumn{2}{|c|}{$\mathrm{R} \$ 80,112$} \\
\hline & Effectiveness (life-years saved) & 13.41 & 9.46 \\
\hline & Effectiveness (QALY saved) & 11.20 & 7.91 \\
\hline & $\begin{array}{c}\text { Differential effectiveness } \\
\text { (QALY) }\end{array}$ & \multicolumn{2}{|c|}{3.28} \\
\hline & ICER (costs per QALY saved) & \multicolumn{2}{|c|}{$\mathrm{R} \$ 24,413$} \\
\hline \multirow{6}{*}{ Discounted } & Aggregated costs & $\mathrm{R} \$ 100,920$ & $\mathrm{R} \$ 43,866$ \\
\hline & Differential cost & \multicolumn{2}{|c|}{$\mathrm{R} \$ 57,055$} \\
\hline & Effectiveness (life-years saved) & 11.79 & 8.54 \\
\hline & Effectiveness (QALY saved) & 9.85 & 7.15 \\
\hline & $\begin{array}{c}\text { Differential effectiveness } \\
\text { (QALY) }\end{array}$ & \multicolumn{2}{|c|}{2.70} \\
\hline & ICER (Costs per QALY saved) & \multicolumn{2}{|c|}{$\mathrm{R} \$ 21,156$} \\
\hline
\end{tabular}


discount rate, age at implant, and conventional mortality (Figure 2); however, the low values of the discount rate resulted in a change in costs per QALY, which proved to be substantially lower than those resulting from the high value. No values of the one-way sensitivity analysis are under the incremental costs per QALY above the WTP thresholds of one or three times the Brazilian GDP per capita.

Figure 3 shows the simulated costs per QALY of the probabilistic sensitivity analysis, where each dot corresponds to the resulting cost per QALY of a model iteration, and the continuous line shows the WTP threshold of $R \$ 105,723$ per QALY. Results show a mean cost per QALY of $\mathrm{R} \$ 21,258$ (median cost per QALY of $\mathrm{R} \$ 21,250$, 95-percent Credible Interval [R $\$ 15,293$ - $R \$ 46,619]$ per QALY) after 1,000 iterations; $99.8 \%$ and $92.9 \%$ of the simulations result in costs per QALY below the three (long-dashed lined in Figure 3) and one (short-dashed line in Figure 3) times GDP per capita WTP threshold, respectively.

\section{Discussion}

Our results indicate that ICD therapy is highly cost effective for 1.5 PP patients in the Brazilian healthcare system, which at an ICER of R $\$ 21,156$ per QALY is less than one-third the WTP value of $\mathrm{R} \$ 105,723$ (three times GDP per capita). This finding is robust, with a sensitivity analysis indicating that the cost effectiveness is preserved in virtually all reasonable variations of model inputs.

Prior estimates of the cost effectiveness of ICD therapy have been performed in the broader primary prevention population. Mark et al. ${ }^{7}$ performed an analysis of the randomized SCD-HeFT trial and found ICD therapy to be economically attractive at $\$ 41,530 / \mathrm{QALY}$ (at a WTP of $\$ 100,000)$ in the US healthcare system. An analysis in the healthcare system of a European country using a metaanalysis of six randomized PP trials and the same model used in this study showed similar results. $\left.{ }^{6}\right)$. The costeffectiveness of ICD therapy has also been confirmed in

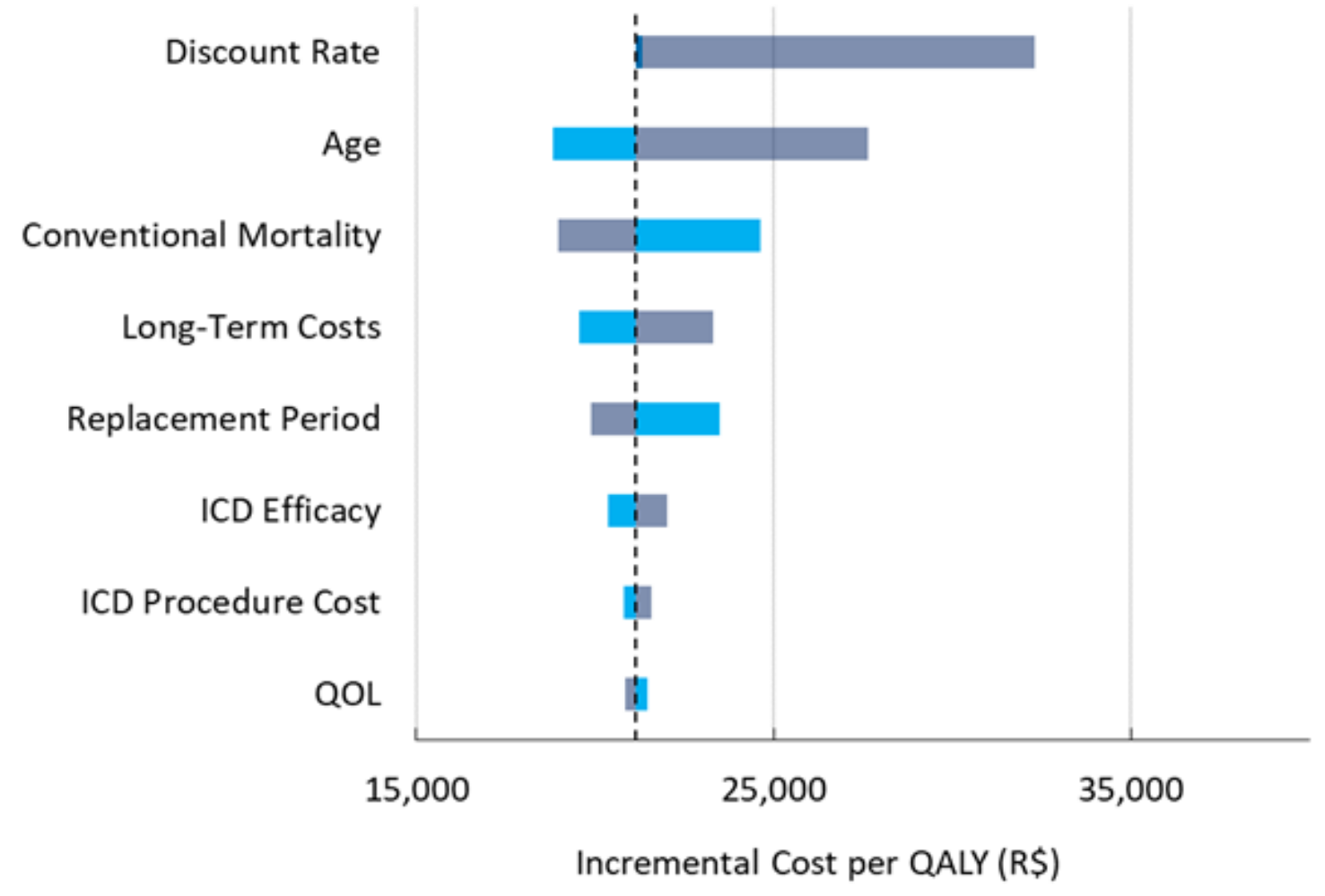

Parameter Input High $\square$ Parameter Input Low 


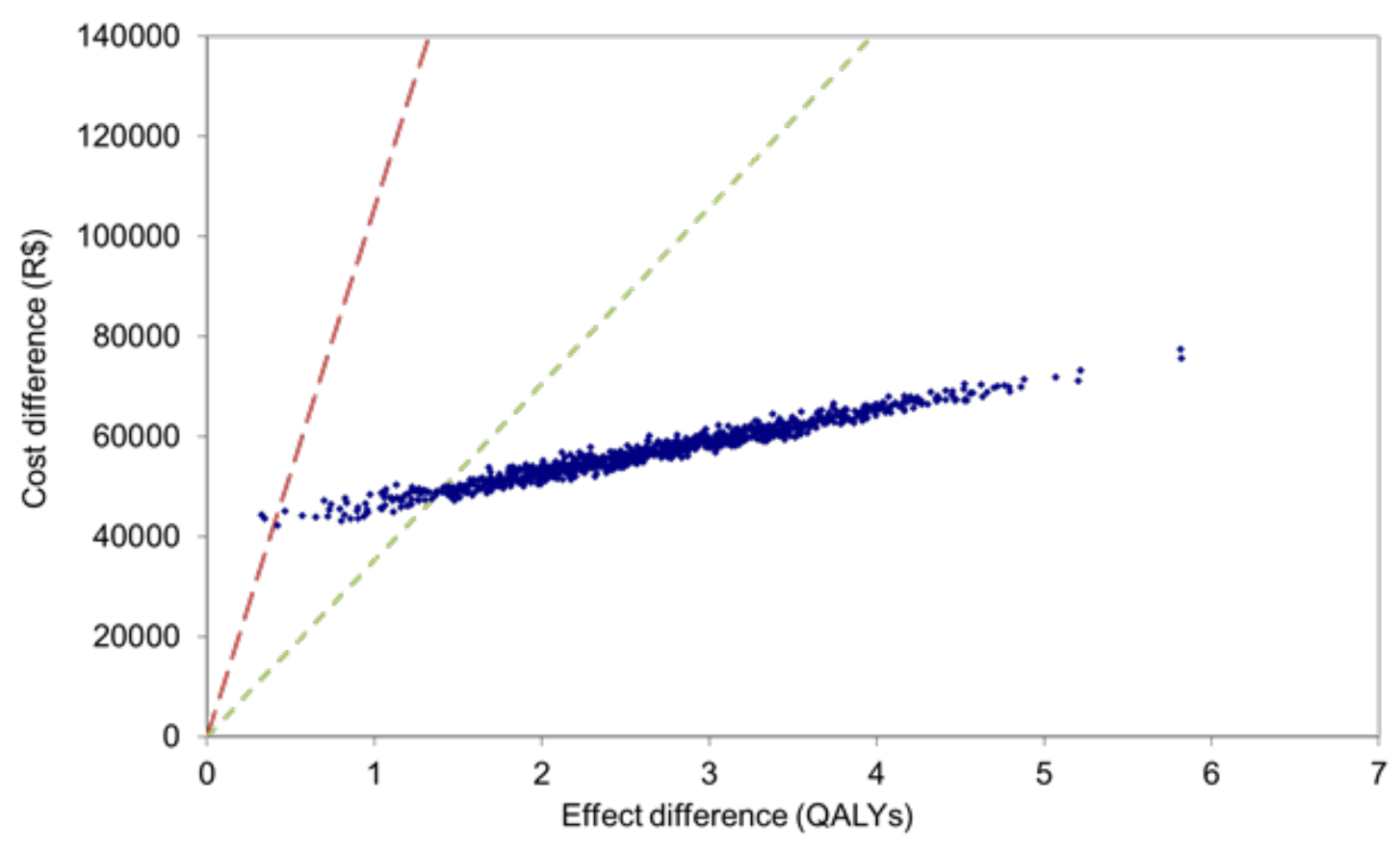

Figure 3 - Probabilistic Sensitivity Analysis scatterplot. The range of ICER given probabilistic variation in model inputs. All ICER values remained below the willingness to pay threshold. Dots represent individual ICER data points, the green dashed line represents WTP at $1 x$ GDP per capita, the red dashed line represents WTP at 3x GDP per capita.

a real world setting outside of clinical trials. ${ }^{29}$ However, Ribeiro et al. ${ }^{30}$ performed an evaluation specific to the Brazil healthcare system, concluding that the ICER was elevated in both the public (R\$68,318/QALY) and private (R\$90,942/QALY) perspectives relative to the WTP, based on three times GDP per capita in 2007 (R \$40,545).

The cost effectiveness of ICD therapy in Brazil has clearly improved since the 2010 assessment, and this can be explained by several factors. First, the model is highly sensitive to the longevity of ICD therapy, which has improved significantly over time. Ribeiro et al. $^{30}$ assumed a replacement interval of five years, based on expectations of devices manufactured in the 1990's, while the current model assumes a median replacement interval of 9.5 years, reflecting advancements in device longevity reported in both the literature and recent product performance reports from device manufacturers. ${ }^{21,31}$ Extended longevity results in fewer ICD reimplantation costs in the model. Second, while this report has used the same approach as the WTP (WHO recommendation of three times GDP per capita), the GDP per capita in Brazil indicates a WTP that has more than doubled when compared to 2007 levels ( $\mathrm{R} \$ 105,723$ versus $\mathrm{R} \$ 40,545)$. Economic growth increases the ability to extend one's life saving benefits of ICD therapy to more people. Third, the model is sensitive to the efficacy of ICD therapy, which has improved relative to the prior report, reducing the number needed to treat in order to save one life from 13 to $10^{10,32}$. Other factors, such as the cost of devices and related hospitalizations may also have contributed to the observed differences between the current and former reports of cost-effectiveness.

Despite convincing evidence from multiple randomized clinical trials ${ }^{1,3,33}$, strong recommendations in international society guidelines, ${ }^{4}$, and corroboration of mortality benefits in the Brazilian healthcare system, ${ }^{11}$ ICD therapy remains underutilized. In a seven-year period, 3,295 ICD implants were reported within the Brazilian National Health System . ${ }^{11}$ placing the annual rate of ICD use at 2-3 implants per million in the Brazilian population. By comparison, the average rate of ICD implantation in Europe is approximately 100 implants per million. ${ }^{34}$ To the extent that economic factors play a role, this study provides information for decision makers to direct 
scarce resources first toward those who can benefit the most. While it remains cost effective to treat the PP population with ICD therapy, from an economic standpoint, a priority should be placed on treating patients with a $1.5 \mathrm{PP}$ indication.

It is important, however, to acknowledge the limitations of this analysis. The Improve SCA trial was not randomized, but the mortality analysis from the trial adjusted for baseline characteristics are likely to have an impact on mortality, and the effectiveness of ICD therapy has been replicated in non-randomized observational trials. Costs and benefits were modeled beyond the timeline of direct observation in the Improve SCA trial; however, this is a standard approach in economic modeling and necessary for the proper perspective for decision makers. Patients in the Improve SCA trial were not all from Brazil, yet they were from countries of similar economic development. Further, ICD therapy application is well developed and largely standardized around the world. Conclusions from this report are not generalizable beyond the 1.5 PP population in the Brazilian public healthcare system.

\section{Conclusion}

Developments over time, including identification of the 1.5 PP population of high-risk patients, improved ICD longevity, and economic growth has led to improved cost effectiveness of ICD therapy. ICD therapy in this context should be considered highly cost effective and represents an economically efficient way to address the underutilization of ICD therapy in indicated patients in Brazil.

\section{References}

1. Bardy GH, Lee KL, Mark DB, Poole JE, Packer DL, Boineau R, et al. Amiodarone or an implantable cardioverter-defibrillator for congestive heart failure. [Internet]. 352nd ed. Vol. 352, The New England journal of medicine. United States; 2005. p. 225-37.[Cited in 2020 Jul 10]Available from: https:// pubmed.ncbi.nlm.nih.gov/15659722

2. Moss AJ, Schuger C, Beck CA, Brown MW, Cannom DS, Daubert JP, et al. Reduction in inappropriate therapy and mortality through ICD programming. [Internet]. 367th ed. Vol. 367, The New England journal of medicine. United States; 2012. p. 2275-83. [Cited in 2020 Jul 12] Available from: https://pubmed.ncbi.nlm.nih.gov/23131066

3. Al-Khatib SM, Hellkamp A, Bardy GH, Hammill S, Hall WJ, Mark DB, et al. Survival of patients receiving a primary prevention implantable cardioverterdefibrillator in clinical practice vs clinical trials. [Internet]. 309th ed. Vol.309, JAMA. United States; 2013. p. 55-62. [Cited in 2016 Feb 12]. Available from: https://libcontent.medtronic.com:2908/pubmed/23280225

4. Epstein AE, DiMarco JP, Ellenbogen KA, Estes NAM 3rd, Freedman RA, Gettes LS, et al. ACC/AHA/HRS 2008 Guidelines for Device-Based

\section{Acknowledgements}

We are grateful to Brian Van Dorn, MS, of Medtronic for providing the utility estimates based on the Improve SCA(10) quality of life data and Janet E O'Brien, MS, of Medtronic, for medical writing assistance.

\section{Potential Conflict of Interest}

Medtronic; DA. Rodriguez: proctor/lecture fees: Boston Scientific, proctorship: Biosense Webster, St. Jude Medical/ Abbott, steering committee fees: Medtronic.

\section{Sources of Funding}

This study was funded by Medtronic, Minneapolis, MN .

\section{Study Association}

This study is not associated with any thesis or dissertation work.

\section{Ethics approval and consent to participate}

This article does not contain any studies with human participants or animals performed by any of the authors.

\section{Author contributions}

Conception and design of the research: Wherry K, Holbrook R. Acquisition of data: Fujii F. Analysis and interpretation of the data: Wherry K, Holbrook R, Fujii F. Statistical analysis: Wherry K, Holbrook R, Higuera L. Writing of the manuscript: Wherry K, Holbrook R, Higuera L. Critical revision of the manuscript for intellectual content: Rodriguez D, Fujii F.

Therapy of Cardiac Rhythm Abnormalities: a report of the American College of Cardiology/American Heart Association Task Force on Practice Guidelines (Writing Committee to Revise the ACC/AHA/NASPE 2002 Guideline Update for Implantation of Cardiac Pacemakers and Antiarrhythmia Devices): developed in collaboration with the American Association for Thoracic Surgery and Society of Thoracic Surgeons. [Internet]. 117th ed. Vol. 117, Circulation. United States; 2008. p. e350408. [Cited in 2020 Feb 12].Available from: https://pubmed.ncbi.nlm.nih. gov/18483207

5. Priori SG, Blomstrom-Lundqvist C, Mazzanti A, Blom N, Borggrefe M, Camm J, et al. 2015 ESC Guidelines for the management of patients with ventricular arrhythmias and the prevention of sudden cardiac death: The Task Force for the Management of Patients with Ventricular Arrhythmias and the Prevention of Sudden Cardiac Death of the European Society of Cardiology (ESC). Endorsed by: Association for European Paediatric and Congenital Cardiology (AEPC). [Internet]. 36th ed. Vol. 36, European heart journal. England; 2015. p. 2793-867. [Cited in 2016 Feb 23].Available from: https://pubmed.ncbi.nlm.nih.gov/26320108 
6. Cowie MR, Marshall D, Drummond M, Ferko N, Maschio M, Ekman $\mathrm{M}$, et al. Lifetime cost-effectiveness of prophylactic implantation of a cardioverter defibrillator in patients with reduced left ventricular systolic function: results of Markov modelling in a European population. [Internet]. 11th ed. Vol. 11, Europace : European pacing, arrhythmias, and cardiac electrophysiology : journal of the working groups on cardiac pacing, arrhythmias, and cardiac cellular electrophysiology of the European Society of Cardiology. England; 2009. p. 716-26.[Cited in 2019 July 12] Available from: https://libcontent.medtronic.com:2908/ pubmed/19359333

7. Mark DB, Nelson CL, Anstrom KJ, Al-Khatib SM, Tsiatis AA, Cowper $\mathrm{PA}$, et al. Cost-effectiveness of defibrillator therapy or amiodarone in chronic stable heart failure: results from the Sudden Cardiac Death in Heart Failure Trial (SCD-HeFT). [Internet]. 114th ed. Vol. 114, Circulation. United States; 2006. p. 135-42. Available from: https://libcontent. medtronic.com:2908/pubmed/16818817

8. Chia YMF, Teng T-HK, Tan ESJ, Tay WT, Richards AM, Chin CWL, et al. Disparity Between Indications for and Utilization of Implantable Cardioverter Defibrillators in Asian Patients With Heart Failure [Internet]. 10th ed. Vol. 10, Circulation. Cardiovascular quality and outcomes. United States; 2017.[Cited in 2018 Mar 21]. Available from: https://libcontent.medtronic.com:2908/pubmed/29150533

9. Zhang S, Singh B, Rodriguez DA, Chasnoits AR, Hussin A, Ching C-K, et al. Improve the prevention of sudden cardiac arrest in emerging countries: the Improve SCA clinical study design. [Internet]. 17th ed. Vol. 17, Europace : European pacing, arrhythmias, and cardiac electrophysiology : journal of the working groups on cardiac pacing, arrhythmias, and cardiac cellular electrophysiology of the European Society of Cardiology. England; 2015. p. 1720-6. [Cited in 2019 Mar 12]. Available from: https://libcontent.medtronic.com:2908/pubmed/26037794

10. Zhang S, Ching C-K, Huang D, Liu Y-B, Rodriguez-Guerrero DA, Hussin A, et al. Utilization of implantable cardioverter-defibrillators for the prevention of sudden cardiac death in emerging countries: Improve SCA clinical trial. [Internet]. 17th ed. Vol. 17, Heart rhythm. United States; 2020. p. 468-75.[Cited in 2018 June 15]. Available from: https:// pubmed-ncbi-nlm-nih-gov.libcontent.medtronic.com:2443/31561030

11. Migowski A, Ribeiro AL, Carvalho MS, Azevedo VMP, Chaves RBM, Hashimoto L de A, et al. Seven years of use of implantable cardioverterdefibrillator therapies: a nationwide population-based assessment of their effectiveness in real clinical settings. [Internet]. 15th ed. Vol. 15, BMC cardiovascular disorders. England; 2015. p. 22. [Cited in 2018 Jan 23]. Available from: https://libcontent.medtronic.com:2908/pubmed/25888219

12. Lessa F, Ferraz MB. Health technology assessment: the process in Brazil. [Internet]. 41st ed. Vol. 41, Revista panamericana de salud publica = Pan American journal of public health. United States; 2017. p. e25.[Cited in 2019 Mar 11]. Available from: https://pubmed-ncbi-nlm-nih-gov. libcontent.medtronic.com:2443/28614463

13. Hammill SC, Kremers MS, Stevenson LW, Heidenreich PA, Lang CM, Curtis JP, et al. Review of the registry's fourth year, incorporating lead data and pediatric ICD procedures, and use as a national performance measure. [Internet]. 7th ed. Vol. 7, Heart rhythm. United States; 2010 p. 1340-5. Available from: [Cited in 2019 aug 26].https://pubmed-ncbinlm-nih-gov.libcontent.medtronic.com:2443/20647056

14. Gasparini M, Proclemer A, Klersy C, Kloppe A, Lunati M, Ferrer JBM, et al. Effect of long-detection interval vs standard-detection interval for implantable cardioverter-defibrillators on antitachycardia pacing and shock delivery: the ADVANCE III randomized clinical trial. [Internet]. 309th ed. Vol. 309, JAMA. United States; 2013. p. 1903-11. [Cited in 2020 June 12].Available from: https://pubmed.ncbi.nlm.nih.gov/23652522

15. Saeed M, Hanna I, Robotis D, Styperek R, Polosajian L, Khan A, et al. Programming implantable cardioverter-defibrillators in patients with primary prevention indication to prolong time to first shock: results from the PROVIDE study. [Internet]. 25th ed. Vol. 25, Journal of cardiovascular electrophysiology. United States; 2014. p. 52-9.[Cited in 2018 June 21] Available from: https://pubmed-ncbi-nlm-nih-gov.libcontent.medtronic com:2443/24112717

16. Global Health Observatory data repository[ Cited in 2018 May 30]. Available from: https://www.who.int/gho/en/. 2019.
17. Hussein AA, Baghdy Y, Wazni OM, Brunner MP, Kabbach G, Shao M, et al. Microbiology of Cardiac Implantable Electronic Device Infections. [Internet]. 2nd ed. Vol. 2, JACC. Clinical electrophysiology. United States; 2016. p. 498-505. [Cited in 2019 Feb 21].Available from: https://libcontent. medtronic.com:2908/pubmed/29759872

18. Ghani A, Delnoy PPHM, Ramdat Misier AR, Smit JJJ, Adiyaman A, Ottervanger JP, et al. Incidence of lead dislodgement, malfunction and perforation during the first year following device implantation. [Internet]. 22nd ed. Vol. 22, Netherlands heart journal : monthly journal of the Netherlands Society of Cardiology and the Netherlands Heart Foundation. Netherlands; 2014. p. 286-91. [Cited in 2020 May 17]. Available from: https://pubmed-ncbi-nlm-nih-gov.libcontent.medtronic. com:2443/24807834

19. Li H, Natale A, Zhu W, Greenfield RA, Easley A, Barrington W, et al. Causes and consequences of discontinuation of the implantable cardioverter-defibrillator therapy in non-terminally ill patients. [Internet]. 81st ed. Vol. 81, The American journal of cardiology. United States; 1998. p. 1203-5.[Cited in 2017 May 12]. Available from: https:// pubmed-ncbi-nlm-nih-gov.libcontent.medtronic.com:2443/9604946

20. Eby E, LGS B, MP J. Economic impact of cardiac implantable electronic device infections: cost analysis at one year in a large US health insurer [Internet]. 2020.\{Cited in 2016 May 29] Available from: https://www. tandfonline.com/doi/abs/10.1080/13696998.2020.1751649

21. CRHF. Product Performance Report.[Cited in 2019 Feb 27]. http://wwwp. medtronic.com/productperformance/past-reports.html. Medtronic; 2017.

22. Providencia R, Kramer DB, Pimenta D, Babu GG, Hatfield LA, Ioannou A, et al. Transvenous Implantable Cardioverter-Defibrillator (ICD) Lead Performance: A Meta-Analysis of Observational Studies. [Internet]. 4th ed. Vol. 4, Journal of the American Heart Association. England; 2015. p. 2047-9980. [Cited in 2020 Jul 25].Available from: https://pubmedncbi-nlm-nih-gov.libcontent.medtronic.com:2443/26518666

23. Poole JE, Gleva MJ, Mela T, Chung MK, Uslan DZ, Borge R, et al. Complication rates associated with pacemaker or implantable cardioverter-defibrillator generator replacements and upgrade procedures: results from the REPLACE registry. [Internet]. 122nd ed. Vol. 122, Circulation. United States; 2010. p. 1553-61. [Cited in 2020 May 22]. Available from: https://ibcontent.medtronic.com:2908/pubmed/20921437

24. Tamayo D, Rodríguez V, Rojas M. Outpatient and inpatient costs of heart failure in two hospitals in Bogotá [Internet]. 2013.[Cited in 2020 Set 15]. Available from: http://www.scielo.org.co/scielo.php?pid=S012024482013000400005\&script=sci_arttext\&tlng=pt

25. Brasil. Ministério da Saúde. Coordenação-Geral Avaliacao_Economica_ Brazil2014 . Brasilia;2014.

26. Viegas Andrade M, Noronha K, Kind P, Maia AC, Miranda de Menezes R, De Barros Reis C, et al. Societal Preferences for EQ-5D Health States from a Brazilian Population Survey. [Internet]. 2nd ed. Vol. 2, Value in health regional issues. United States; 2013. p. 405-12. [Cited in 2018 Jun 23] Available from: https://libcontent.medtronic.com:2908/ pubmed/29702778

27. Sanders GD, Hlatky MA, Owens DK. Cost-effectiveness of implantable cardioverter-defibrillators. [Internet]. 353rd ed. Vol. 353, The New England journal of medicine. United States; 2005. p. 1471-80. [ Citado in 2017 Feb 21].Available from: https://ibcontent.medtronic.com:2908/ pubmed/16207849

28. Hutubessy R, Chisholm D, Edejer TT-T. Generalized cost-effectiveness analysis for national-level priority-setting in the health sector. [Internet]. Vol. 1, Cost effectiveness and resource allocation : C/E. England; 2003. p. 8.[Cited in 2019 Out 26]. Available from: https:// libcontent.medtronic.com:2908/pubmed/14687420

29. Thijssen J, van den Akker van Marle ME, Borleffs CJW, van Rees JB, de Bie MK, van der Velde ET, et al. Cost-effectiveness of primary prevention implantable cardioverter defibrillator treatment: data from a large clinical registry. [Internet]. 37th ed. Vol. 37, Pacing and clinical electrophysiology : PACE. United States; 2014. p. 25-34. [Cited in 2018 Aug 18]. Available from: https://libcontent.medtronic.com:2908/ pubmed/23998638 
30. Ribeiro RA, Stella SF, Zimerman LI, Pimentel M, Rohde LE, Polanczyk CA. Cost-effectiveness of implantable cardioverter defibrillators in Brazil in the public and private sectors. [Internet]. 95th ed. Vol. 95, Arquivos brasileiros de cardiologia. Brazil; 2010. p. 577-86. [Cited in 2019 Nov 13]. Available from: https://libcontent.medtronic.com:2908/pubmed/20922266

31. Poli S, Boriani G, Zecchin M, Facchin D, Gasparini M, Landolina M, et al. Favorable Trend of Implantable Cardioverter-Defibrillator Service Life in a Large Single-Nation Population: Insights From 10-Year Analysis of the Italian Implantable Cardioverter-Defibrillator Registry. [Internet]. 8th ed. Vol. 8, Journal of the American Heart Association. England; 2019. p. e012759. [Cited in 2018 Apr 26]. Available from: https://libcontent.medtronic.com:2908/ pubmed/31340695

32. Nanthakumar K, Epstein AE, Kay GN, Plumb VJ, Lee DS. Prophylactic implantable cardioverter-defibrillator therapy in patients with left ventricular systolic dysfunction: a pooled analysis of 10 primary prevention trials. [Internet]. 44th ed. Vol. 44, Journal of the American College of Cardiology. United States; 2004. p. 2166-72.[Cited in 2018 Jan 12]. Available from: https:// libcontent.medtronic.com:2908/pubmed/15582314

33. Moss AJ, Zareba W, Hall WJ, Klein H, Wilber DJ, Cannom DS, et al. Prophylactic implantation of a defibrillator in patients with myocardial infarction and reduced ejection fraction. [Internet]. 346th ed. Vol. 346, The New England journal of medicine. United States; 2002. p. 877-83.[Cited in 2017 Mar 26]. Available from: https://pubmed.ncbi.nlm.nih.gov/11907286
34. Raatikainen MJP, Arnar DO, Zeppenfeld K, Merino JL, Levya F, Hindriks G, et al. Statistics on the use of cardiac electronic devices and electrophysiological procedures in the European Society of Cardiology countries: 2014 report from the European Heart Rhythm Association. [Internet]. 17 Suppl 1. Vol.17Suppl 1, Europace : European pacing, arrhythmias, and cardiac electrophysiology : journal of the working groups on cardiac pacing, arrhythmias, and cardiac cellular electrophysiology of the European Society of Cardiology. England; 2015. p. i1-75.[Cited in 2020 June 25]. Available from: https://libcontent. medtronic.com:2908/pubmed/25616426

35. Auricchio A, Schloss EJ, Kurita T, Meijer A, Gerritse B, Zweibel S, et al. Low inappropriate shock rates in patients with single- and dual/triple-chamber implantable cardioverter-defibrillators using a novel suite of detection algorithms: PainFree SST trial primary results. [Internet]. 12th ed. Vol. 12, Heart rhythm. United States; 2015. p. 926-36.[Cited in 2019 Apr 16]. Available from: https://pubmed.ncbi.nlm.nih.gov/25637563

36. Sweeney MO, Wathen MS, Volosin K, Abdalla I, DeGroot PJ, Otterness MF, et al. Appropriate and inappropriate ventricular therapies, quality of life, and mortality among primary and secondary prevention implantable cardioverter defibrillator patients: results from the Pacing Fast VT REduces Shock ThErapies (PainFREE Rx II) trial. [Internet]. 111th ed. Vol. 111, Circulation. United States; 2005. p. 2898-905.[Cited in 202o may 23]. Available from: https://pubmed.ncbi.nlm.nih.gov/15927965

37. Brasil. Ministério da Saúde. Edital Do Pregao Eletronico No 22/2018 Sistema De Registro De Precos. Brasilia;2018.

\section{*Supplemental Materials}

For additional information, please click here. 